\title{
Assessment of drug use patterns in terms of the WHO patient-care and facility indicators at four hospitals in Southern Ethiopia: a cross-sectional study
}

Kassa Daka Gidebo ${ }^{1}$, Temesgen Sidamo Summoro ${ }^{2 *}$, Zewde Zema Kanche ${ }^{2}$ and Eskinder Wolka Woticha ${ }^{1}$

\begin{abstract}
Background: Patient-centered care is now the goal for virtually all healthcare systems. The aim of this research was to evaluate the patient care quality in regard to drug dispensing in four hospitals in southern Ethiopia namely Wolaita Sodo University teaching and referral hospital (WSUTRH), Tercha zonal hospital (TZH), Sodo Christian hospital (SCH) and Dubo St. Mary's Catholic primary hospital (DSMCPH).

Methods: A cross sectional study was conducted by using the WHO patient care and facility indicators between September 10 and October 20, 2014. Patients who visited the outpatient departments of the four hospitals were selected by systematic random sampling method and interviewed. In total 384 patients were selected based on a rough estimate of proportion of patients visiting to the four hospitals. Facility indicators including the availability of essential drugs list (EDL), national drug formulary, standard treatment guideline (STG) and key drugs were evaluated. Descriptive statistical calculations were performed using SPSS ${ }^{\circledR}$ version 20.0 software.
\end{abstract}

Result: The mean number of drugs was in the range between $1.9 \pm 0.9$ to $2.2 \pm 2.0$. The mean consultation time range was found to be $4.2 \pm 1.6$ to $4.9 \pm 5.0$ min whereas the mean dispensing time was ranged from $96.1 \pm 52.0$ to $152.3 \pm$ $47.6 \mathrm{~s}$. The overall mean number of drug prescribed for the four hospitals was $2.0 \pm 1.2$ and the mean percentage of medications actually dispensed in the hospitals was thus calculated to be 86.3. The mean percentage of medications clearly labeled was 45.4. Patients who knew their dosage forms accurately were 78.8. Among the four hospitals evaluated only one hospital (25\%) had at least a copy of the Ethiopian essential drug list (EDL), standard treatment guideline for hospitals and drug formulary. The mean availability of key drugs in the hospitals was found to be $65.7 \%$.

Conclusion: The result of the present study indicates that the patient consulting time, medications labeling and availability of key drugs in the hospitals are inadequate. The medication labeling practice in the four hospitals is unacceptably low. These patient care indicators need a special attention for improvement.

Keywords: Drug use patterns, Patient care indicators, Facility indicators, Drugs, Ethiopia

\footnotetext{
*Correspondence: teme.yene2003@gmail.com

${ }^{2}$ School of Medicine, College of health Sciences and Medicine, Wolaita Sodo

University, Wolaita Sodo, Ethiopia

Full list of author information is available at the end of the article
} International License (http://creativecommons.org/licenses/by/4.0/), which permits unrestricted use, distribution, and reproduction in any medium, provided you give appropriate credit to the original author(s) and the source, provide a link to the Creative Commons license, and indicate if changes were made. The Creative Commons Public Domain Dedication waiver (http://creativecommons.org/publicdomain/zero/1.0/) applies to the data made available in this article, unless otherwise stated. 


\section{Background}

Health care and quality are inextricably linked, therefore to provide health care services without concern for quality is unprofessional and potentially deadly [1]. Appropriate treatment of commonly occurring diseases and injuries and the provision of essential drugs are the two vital components of the primary health care concept as per the Alma-Ata declaration of 1978 [2].

Drug dispensing is a process that ends with a client leaving a drug outlet with a defined quantity of medication(s) and instructions on how to use drugs. The quantity of drugs dispensed depends on their availability and amount a patient needs for a given condition. Thus information available from dispensers may include: $\operatorname{drug}(\mathrm{s})$ prescribed, dose(s) prescribed, mean number of items per prescription, percentage of items prescribed that were actually supplied (an indicator of availability), percentage of drugs adequately labeled, quantity of medications and cost of each item or prescription. These data may be obtained from records kept at the drug outlet either in electronic or manual form [3].

Each of these indicators has its own purpose in drug use evaluation. Patient consulting and dispensing times have the purpose of measuring the time that both medical personnel and dispensing personnel spend with patients in the process of consulting, prescribing and dispensing drugs. The time that prescribers and dispensers spend with each patient may indicate the potential quality of diagnosis and treatment. The percentage of drugs actually dispensed is used to measure the degree to which health facilities are able to provide the drugs which were prescribed, the percentage of drugs adequately labeled help measure whether dispensers included essential information about the medications for patients. Patient knowledge of correct medication helps evaluate the effectiveness of the information given to patients on the dosage schedule of the drugs they receive [4].

The ability to prescribe drugs rationally is influenced by many features of the working environment. Two particularly important components are an adequate supply of essential drugs and access to unbiased information about these drugs. Without these it is difficult for health personnel to function effectively. The world health organization has set criteria used for the evaluation of a health facility. The criteria include availability of essential drugs list or formulary and key drugs [3, 4].

Essential drugs are one of the tools needed to fight ill health. By increasing access to essential drugs and their rational use, we could improve health status and secure development gains [5]. "Essential drugs are those that satisfy the health care needs of the majority of the population; they should therefore be available at all times, in adequate amounts and in the appropriate dosage forms" [6]. This concept was introduced to accelerate the positive impacts of drugs on health status, particularly for developing countries [5, 7]. When investigating drug use, the investigation should determine whether a national essential drugs list, local formulary, or equivalent reference material exists, when this material underwent its most recent revision, and in what form it has been distributed to health facilities [3, 4, 7].

Worldwide, more than half of all medicines are prescribed, dispensed, or sold improperly, and $50 \%$ of patients fail to take them correctly [3-6]. About one third of the world's population lacks access to essential medicines [8]. A survey conducted in 8 hospitals in southern Ethiopia that investigated their prescription patterns concluded that irrational prescribing, as evidenced by high mean number of drugs prescribed per encounter, high percentage of injections, and high percentage of antibiotic use, was prevalent in the studied region [9]. A more recent study in four hospitals in the same region revealed that there was excessive use of antibiotics and injectable medications in the hospitals [10]. Another study that evaluated the WHO patient care indicators in South West Ethiopia also reported that there was a lower than the set values of patient knowledge on their medications, availability of essential guidelines and key drugs in stock in the health facilities [11].

Assessment of drug use patterns with the WHO drug use indicators is becoming increasingly necessary to promote rational drug use in developing countries $[4,12]$. Before activities are started to promote rational drug use, an effort should be made to describe and quantify the situation. Several well-established survey methods are available for this purpose. One such assessment method is a prescribing and patient care survey using the WHO health facility drug use indicators. These quantitative indicators are now widely accepted as a global standard for problem identification and have been used in over 30 developing countries [13].

The aim of this study was to evaluate drug use in terms of WHO patient care and facility indicators in four hospitals located in Southern Ethiopia. The hospitals included were Wolaita Sodo University Teaching Referral hospital (WSUTRH), Tercha Zonal hospital (TZH), Sodo Christian Hospital (SCH) and Dubo St. Mary's Catholic primary hospital (DSMCPH).

\section{Methods}

A cross sectional study for WHO patient care and facility indicators was conducted on patients who visited the outpatient departments of the four hospitals between September 10 and October 20, 2014.

The sample size calculation was carried out based on the following assumption. The assumptions: Level of confidence $95 \%, 5 \%$ margin of error, and $\mathrm{P}$ is the 
proportion of patients who visited the hospitals and took correct patient care. Since there was no previous studies done on drug use in the hospitals, $\mathrm{p}=50 \%$ was taken to have maximum sample size. Based on these assumptions the actual sample size for the study was computed using the formula for single population proportion:

$$
\mathrm{n}=\frac{(\mathrm{Z} \alpha / 2)^{2} \mathrm{P}(1-\mathrm{p})}{\mathrm{d}^{2}}
$$

Where, $\mathrm{n}=$ sample size, $\mathrm{Z} \alpha / 2=$ Critical value $=1.96$, $\mathrm{P}=$ proportion of patients who had taken correct patient care in the hospitals $(0.5)$ and $d=$ marginal error $=0.05$.

Then $\mathrm{n}=\frac{(1.96)^{2}(0.5)(0.5)}{(0.05)^{2}}=384$

In total 384 patients were selected by systematic random sampling in the four hospitals to minimize bias which can be made due to difference in patient load on different days in a week and variation in pattern of hospital visits for chronic care patients. Sampling frame was estimated from outpatient department visits of hospitals in the month prior to data collection.

Therefore, 96 patients from each hospital were selected for observation and interview for patient care evaluation. Consultation and dispensing times were recorded by observation of actual contact with physicians and pharmacists. Number of drugs dispensed against the number of drugs prescribed per encounter was recorded in pharmacy at the point of prescription filling. For medication labeling and patient knowledge about dispensed medicines, packages were observed and patients were interviewed on exiting the pharmacy. Patients who did not receive any medication, below age of 18 and those who were not on ease to respond interview were excluded from this study.

For WHO facility indicators evaluation; information for availability of an essential drug list (EDL), Standard Treatment Guideline (STG), and National Drug Formulary were collected from health professionals in pharmacies, physician diagnosis rooms and in-patient nursing rooms and from the heads of these units. Availability of key drugs was assessed via the stock management software and through observation of the stock in the store.

The data collection was carried out primarily by the outpatient pharmacists and pharmacy technicians in each hospital after appropriate training and orientation. Adequate labeling of dispensed drugs and patient knowledge about the dispensed drugs were assessed by the investigators. Data was collected according to WHO data collection format in order to assess patient care and facility indicators (Additional file 1). The data collection was supervised on a daily basis by the investigators involved in this study. Completeness of the data was checked every day during the data collection period. The data generated for each hospital were entered into a computer using Statistical Package for the Social Sciences (SPSS) version 20.0 software (IBM Corporation, Armonk, NY, USA) to be edited, cleaned, and analyzed. The data were analyzed descriptively and summarized using tables and a bar chart. The findings were compared and contrasted with other national and international studies.

The mean and percentage value of indicator variables were calculated in this study using the following formula:

1. Mean consultation time $=$ sum of all consultation times/total number of patients consulted.

2. Mean dispensing time $=$ sum of all dispensing times/ total number of samples.

3. Percentage of drugs actually dispensed $=$ number of drugs actually dispensed/number of drugs prescribed $\mathrm{x} 100$.

4. Percentage of drugs adequately labeled $=$ drugs labeled adequately/drugs prescribed x 100 .

5. Percentage of patients aware of the correct dosage $=$ patients with correct knowledge of the dosage of all drugs dispensed/patients interviewed x 100 .

6. Percentage of key medicines available in stock $=$ key drugs available in stock/total no. of key drugs x 100 .

\section{Results}

All participants responded to the interview. Among 384 participants female participants are slightly higher than male and almost half of the participants are in the age range of 31-64 (Table 1).

\section{Patient care indicators}

The summary of the mean number of drugs prescribed, the mean number of drugs actually dispensed, the mean consultation and dispensing time is presented in Table 2.

Educational status of patients and their knowledge on the prescribed medications are summarized in Table 3. As it can be seen from the table among the 384 patients interviewed 54 (14.1\%) were illiterate, 175 (45.6\%) had attended or completed primary school education, 85 $(22.1 \%)$ had attended or completed secondary school

Table 1 Socio-demographic characteristics of patients who attended the four hospitals in southern Ethiopia, October 20, $2014(N=384)$

\begin{tabular}{lllllll}
\hline Hospitals & & TZH & SCH & DSMGH & WSUTRH & Total \\
& & N (\%) & N (\%) & N (\%) & N (\%) & N (\%) \\
\hline Sex & Male & $47(48.9)$ & $53(55.2)$ & $44(45.8)$ & $37(38.5)$ & $182(47.4)$ \\
& Female & $49(51.1)$ & $43(44.8)$ & $52(54.2)$ & $59(61.5)$ & $202(52.6)$ \\
Age range & $18-30$ & $48(50.0)$ & $36(37.5)$ & $39(40.6)$ & $41(42.7)$ & $164(42.7)$ \\
& $31-64$ & $45(46.8)$ & $53(55.2)$ & $55(57.3)$ & $44(45.8)$ & $197(51.3)$ \\
& $>64$ & $3(3.1)$ & $7(7.3)$ & $2(2.1)$ & $11(11.5)$ & $23(6.0)$ \\
\hline
\end{tabular}


Table 2 Summary of patient care indicators in four hospitals in southern Ethiopia, October, 2014

\begin{tabular}{lcrrr}
\hline Patient care Indicators & Hospitals & & \\
\cline { 2 - 5 } & SCH & DSMCPH & TZH & WSUTRH \\
\hline Mean number of drugs prescribed \pm SD & $2.2 \pm 2.0$ & $2.0 \pm 0.9$ & $1.9 \pm 0.9$ & $1.9 \pm 0.8$ \\
Mean number of drugs actually dispensed \pm SD & $1.9 \pm 2.0$ & $1.7 \pm 1.0$ & $1.9 \pm 0.9$ & $1.4 \pm 0.8$ \\
Mean consulting time (in minutes) \pm SD & $4.2 \pm 1.6$ & $4.9 \pm 2.8$ & $4.9 \pm 5.0$ & $4.8 \pm 2.5$ \\
Mean dispensing time (in seconds) \pm SD & $118 \pm 53.8$ & $152.3 \pm 47.6$ & $96.1 \pm 52$ & $110.4 \pm 56$ \\
\hline
\end{tabular}

education and $70(18.2 \%)$ had attended or completed education of a college or above levels.

Percentage of drugs actually dispensed in four hospitals range from $71 \%$ (WSUTRH) to $100 \%$ (TZH), percentage of adequately labeled drugs range from $19.4 \%$ (WSUTRH) to $62 \%$ (TZH) and patients who knew the dosage of the dispensed drugs ranges from $74.5 \%$ (DSMGH) to $81.6 \%(\mathrm{TZH} / \mathrm{SCH})$. The percentage of drugs actually dispensed as well as adequately labeled, and patients who knew the dosage of their medication in the four hospitals studied are summarized in Fig. 1 for comparison.

\section{Facility Indicators (Availability of essential resources)}

Except the WSUTRH none of the outpatient pharmacy departments in the hospitals have at least either a copy of National drug formulary, EDL or STG. Availability of the key drugs in the outpatient pharmacy of the hospitals was also evaluated. Percentage of availability of the key drugs for $\mathrm{SCH}$, DSMCPH, TZH and WSUTRH is $62.5,81.3,68.8$ and 50, respectively (Table 4).

\section{Discussion}

\section{Consulting and dispensing time}

During a consultation, a physician has to make a complete patient evaluation, select the appropriate medications, and enable for proper patient- physicians interaction [14]. The overall mean of consulting time in this study was found to be $4.7 \pm 3.0 \mathrm{~min}(\mathrm{SCH}=4.2 \pm 1.6$, $\mathrm{DSMCPH}=4.9$ $\pm 2.8, \mathrm{TZH}=4.9 \pm 5.0$, and WSUTRH $=4.8 \pm 2.5$ ). This is shorter than what was reported in North West Ethiopia but longer than reported in Jordan and India which were 3.9 and $4 \mathrm{~min}$ respectively $[11,14]$. Mean consulting time in studies in six European countries was $10.7 \mathrm{~min}$ and in the United Arab Emirates it was 10 min $[15,16]$. These times are much higher than the results of this present study. Times reported in this current study, as well as in the studies reviewed, are well below the optimal consultation time of $\geq 30 \mathrm{~min}$ recommended for conducting proper historytaking, complete physical examination, appropriate health education instructions and prescribing therapy [17]. This current study shows that the consultation time is too short to enable physicians to communicate with their patients regarding their therapy and illness.

Patient compliance directly depends on his/her knowledge about the drug. Therefore an adequate dispensing time is a necessary step towards improving patient care [18]. The mean dispensing time in current study of $119.1 \pm$ $52.4 \mathrm{~s}$ is longer than reported in other studies in Ethiopia. It is longer when compared to studies in Jordan, in United Arab Emirates, and in Sharjah which were $28.8 \mathrm{~s}, 68 \mathrm{~s}$, and 89 s, respectively [11, 16, 19]. A study in Nepal showed $52 \mathrm{~s}$ mean dispensing time which is longer than another study in India [20, 21]. The dispensing time observed in these studies is found to be very low compared to the WHO recommendation that a pharmacist should spend at least $3 \mathrm{~min}$ in orienting each patient [14, 22]. Since dispensing is terminal step for patient contact with health care provider a pharmacist can hardly explain about the dosage

Table 3 Distribution of patients' knowledge of dispensed drugs and their literacy level in the four hospitals; October, 2014

\begin{tabular}{|c|c|c|c|c|c|c|c|c|c|c|}
\hline \multirow{2}{*}{$\begin{array}{l}\text { Knowledge questions } \\
\text { on dispensed drugs }\end{array}$} & \multicolumn{2}{|l|}{ Illiterate } & \multicolumn{2}{|l|}{$\begin{array}{l}\text { Primary } \\
\text { school }\end{array}$} & \multicolumn{2}{|c|}{ Secondary School } & \multicolumn{2}{|c|}{ College and above } & \multicolumn{2}{|l|}{ Total } \\
\hline & Yes, N (\%) & No, N (\%) & Yes, N (\%) & No, N (\%) & Yes, N (\%) & No, N (\%) & Yes, N (\%) & No, N (\%) & Yes, N (\%) & No, N (\%) \\
\hline $\begin{array}{l}\text { Do you remind the name } \\
\text { of drug }(s) \text { ? }\end{array}$ & $19(5.0)$ & $35(9.1)$ & $148(38.6)$ & $27(7.0)$ & 75 (19.5) & $10(2.6)$ & $68(17.7)$ & $2(0.5)$ & $310(80.7)$ & 74 (19.3) \\
\hline $\begin{array}{l}\text { Do you know the dose of } \\
\text { drug }(s) ?\end{array}$ & $15(3.9)$ & $39(10.1)$ & $139(36.2)$ & $36(9.4)$ & $74(19.3)$ & $11(2.9)$ & $70(18.2)$ & $0(0.0)$ & $298(77.6)$ & $86(22.4)$ \\
\hline $\begin{array}{l}\text { Do you know the duration } \\
\text { of treatment? }\end{array}$ & $11(2.9)$ & $43(11.2)$ & $54(40.1)$ & $21(5.5)$ & $77(20.0)$ & $8(2.1)$ & $70(18.2)$ & $0(0.0)$ & $312(81.3)$ & $72(18.7)$ \\
\hline $\begin{array}{l}\text { Do you know the frequency } \\
\text { of administration? }\end{array}$ & $19(5.0)$ & $35(9.1)$ & $145(37.8)$ & $30(7.8)$ & $71(18.5)$ & $14(3.6)$ & $67(17.4)$ & $3(0.8)$ & $302(78.4)$ & $82(21.6)$ \\
\hline $\begin{array}{l}\text { Do you know the possible } \\
\text { side effect }(s) \text { ? }\end{array}$ & $20(5.2)$ & $34(8.9)$ & $153(39.9)$ & $22(5.7)$ & $70(18.2)$ & $15(3.9)$ & $70(18.2)$ & $0(0.0)$ & $313(81.5)$ & $71(18.5)$ \\
\hline
\end{tabular}




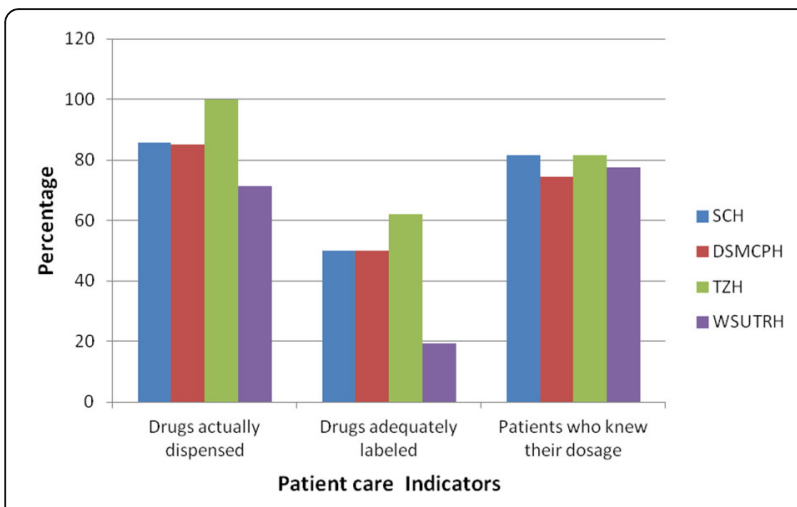

Fig. 1 Comparison of some patient care indicators in the four hospitals; October 2014

regimen, any side effect of drug therapy and precautions to be taken along with appropriate labeling of envelope in such a short period of time. But a study conducted in Niger reported $195 \mathrm{~s}$ which is excellent compared to the WHO recommended dispensing time [14].

\section{The percentage of drugs actually dispensed}

The percentage of drugs actually dispensed is one of the indicators of the availability of essential drugs in health facilities. It may indicate the rationality of drug use in terms of optimum cost. An inadequate drug supply has implications for patients' health status, is inconvenient for patients and jeopardizes their trust in the health system [18]. The mean percentage of actually dispensed drugs was 86.3 and this is greater than a study report of South West Ethiopia which was $83.4 \%$ [11]. Comparable studies, all conducted in India, reported much lower values than found in our study $[14,23,24]$. We found that the percentage of drugs dispensed in the four hospitals studied, was lower than the standard ideal value $(100 \%)$. One study in Saudi Arabia reported $99.6 \%$ of prescribed drugs were dispensed [17].

\section{The percentage of drugs adequately labeled}

Providing adequate information to patients about their drugs is an essential principle of rational pharmacotherapy, since a patient's level of knowledge about his/her medication is highly associated with a favorable outcome of the therapy. Inadequate labeling may not only result in poor information on drug use but also in poor compliance with the dose regimen $[3,4]$. The percentage of drugs adequately labeled ranges from 19.4 to 62.2. The higher value shows that $37.8 \%$ of the medications labeled inadequately whereas $80.6 \%$ were inadequately labeled in the case of the lower value. This shows that there is a very poor medication labeling practice in the hospitals when compared to the standard WHO value which is $100 \%$. It can be said that an appropriate drug labeling system is not established in any of the hospitals. There was an observed attempt to affix a separate labeling paper on medication containers by some pharmacy professionals in TZH. The WHO recommends that each drug label should include at least the patient

Table 4 Availability of key drugs in four hospitals in south Ethiopia, October, 2014

\begin{tabular}{|c|c|c|c|c|}
\hline \multirow[t]{2}{*}{ Key Drugs } & \multicolumn{4}{|c|}{ Hospitals } \\
\hline & $\mathrm{SCH}$ & DSMCPH & $\mathrm{TZH}$ & WSUTRH \\
\hline Amoxicillin & $\checkmark$ & $\checkmark$ & $\checkmark$ & $\checkmark$ \\
\hline Oral rehydration salt (ORS) & $\checkmark$ & $\checkmark$ & $\checkmark$ & $\checkmark$ \\
\hline Arthemeter/Lumefantrine & $\checkmark$ & $\checkmark$ & $\checkmark$ & $\checkmark$ \\
\hline Mebendazole tablet & $\checkmark$ & $\checkmark$ & $\checkmark$ & $\checkmark$ \\
\hline Tetracycline eye ointment & $\checkmark$ & $\checkmark$ & $\checkmark$ & $\checkmark$ \\
\hline Paracetamol & $\checkmark$ & $\checkmark$ & $\checkmark$ & $\checkmark$ \\
\hline Refampicin/Isoniazide/Pyrazinamide/Ethambutol & - & $\checkmark$ & - & - \\
\hline Medroxyprogestrone (Depo) Injection & - & $\checkmark$ & - & - \\
\hline Ergometrine maleate injection /tablet & - & $\checkmark$ & $\checkmark$ & - \\
\hline Ferrous sulphate + Folic acid & $\checkmark$ & $\checkmark$ & $\checkmark$ & $\checkmark$ \\
\hline Pentavalent.DPT.Hep.Hib vaccine & - & - & $\checkmark$ & - \\
\hline Adrenaline $0.1 \%$ injection & - & $\checkmark$ & - & - \\
\hline Antirabies vaccine & - & - & - & - \\
\hline Oxytocine 10 units & $\checkmark$ & $\checkmark$ & $\checkmark$ & - \\
\hline Insulin Zinc Suspension & $\checkmark$ & - & $\checkmark$ & $\checkmark$ \\
\hline Normal saline & $\checkmark$ & $\checkmark$ & - & - \\
\hline Percentage of availability of key drugs & 62.5 & 81.3 & 68.8 & 50 \\
\hline
\end{tabular}

$\checkmark=$ availability of the item (s); - = absence of the item (s) or stock out 
name, the name of the drug, the dose regimen and the dose, and the frequency and route of administration [4, 25]. More than a half of the patient medications in this study missed such essential information.

Apart from noting that the medication labeling is poor in this study; the result can be compared and contrasted with other studies. A study in south west Ethiopia revealed that the mean percentage of medications adequately labeled was $70 \%$ which is much better than the result of this study. In a study done by the Federal Ministry of Ethiopia about $43 \%$ the medications were inadequately labeled which is also better than in present study (where in mean $54.6 \%$ of the dispensed medications were inadequately labeled). However, there are similar values which were reported of hospitals in South India and West Bengal in Eastern India $[23,24]$.

\section{The Percentage of patients who knew their medications correctly}

Dispensing is the end point of contact between pharmacist and patient or the patient's attendant. At this point it is the duty and responsibility of pharmacist to provide adequate information on proper use of drugs [14]. In this study the cumulative mean percentage of patients who knew their medications correctly was 78.8. Table 3 highlights the importance of the literacy level of the patients on their knowledge of the dispensed drugs. As the literacy level increases the knowledge of the patients gets increased.

The above mentioned patient knowledge is lower compared to the WHO recommended value which is $100 \%$. But it is encouraging in comparison to those values in different local and international studies. For example, in South West Ethiopia the mean percentage of patients who knew their medications in different health facilities was found to be 72.83 [11]. An even lower value was reported (43\%) in a study conducted by Federal Ministry of Ethiopia [26]. A prospective cross-sectional descriptive study in a teaching hospital in Western Nepal, the patient's knowledge on correct drug dosage was reported to be $81 \%$. Similar studies revealed $52.8 \%$ in Chennai, India, $55 \%$ in Cambodia, $70 \%$ in Brazil and $80.8 \%$ in pediatric patients in India [20]. A recent study in India showed a much lower value of patients' awareness of their medications [14]. A study in Saudi Arabia revealed $79.3 \%$ of patients had knowledge about their medications [17]. Dispensing practice should mean more than simple issuance of the prescribed or requested items in order to achieve the desired therapeutic goal. The quality and quantity of the dispensed items as well as appropriate drug information determines the success of drug therapy. Pharmacists need to assure patients understand about the medications dispensed for them [27].

\section{Availability of essential resources}

One sign that the concept of essential drugs has been accepted is the development, dissemination and use of a national essential drugs list, a local essential drugs formulary, or equivalent reference material on essential drugs, such as drug information sheets. The availability of such drug information is one cornerstone for rational prescribing [4]. In this study only one out of the four hospitals had a copy of EDL, national drug formulary and STG during the evaluation period. This makes the overall availability $25 \%$ which is much lower than in other studies. A study in south west Ethiopia showed that the availability was $50 \%$ [11]. The availability for 10 health centers in Saudi Arabia was found to be $90 \%$ [17]. However, the availability of the present study can be said to be better than a study in India where $0 \%$ availability was reported [14].

The overall mean percentage of key drugs in stock in the four hospitals was very low $(65.7 \%)$ compared with the optimal value $(100 \%)$. The minimum to maximum range was between $50 \%$ and $81.3 \%$. The evaluation was made in terms of the drugs listed in Table 4 most of which are recommended by Federal Ministry of health of Ethiopia as tracer drugs for the hospitals in Ethiopia. The availability of key drugs is lower compared to that of a study reported in India which was $73 \%$, but greater than that of another study in United Arab Emirates which was $59.2 \%[14,16]$.

\section{Limitations}

This study examined drug use patterns in terms of the WHO patient care and facility indicators. It only measured the WHO set criteria for patient care to assess the drug use patterns in the hospitals without addressing any of the associated factors affecting the drug use. To determine these factors, further study is needed. Also the actual use of the prescribed drugs by the patients was not included in present study as it is difficult to be sure whether the patients took the drugs or not according to the prescribers' instruction. The findings of this study only describe the drug prescribing and dispensing patterns in the outpatient departments of the hospitals. Thus it doesn't reflect the drug use in inpatient wards of the hospitals.

\section{Conclusion and recommendation}

Attention needs to be given to finding a solution to the short consultation times. The consultation time is pivotal in determining appropriate prescribing and use of drugs. Short consultation times, as found in the four hospitals we studied, may negatively impact patient outcomes. Even though the dispensing time in this study was relatively longer compared to other studies still it is shorter than the recommended level. There was very 
poor labeling of the medications. There is a need of investigating the associated factors with the low patient care parameters. Systemic changes are needed to improve patients' knowledge of their medications, deliver appropriate patient advice and adequately label of the medications. Essential drug supply management systems should be established to ensure availability of key drugs in the outpatient pharmacies of the hospitals.

\section{Additional file}

Additional file 1: A WHO Patient care Indicators filling format. B Check list for partial study of WHO patient care indicators. C WHO Facility Indicators filling check list. D WHO Facility Indicators filling format. (DOC $463 \mathrm{~kb}$ )

\section{Abbreviations}

DSMCPH: Dubo St. Mary's catholic primary hospital; EDL: Essential drugs list of Ethiopia; FMOH: Federal Ministry of health of Ethiopia; ORS: oral rehydration salt; SCH: Sodo Christian hospital; SPSS: Statistical Package for the Social Sciences; STG: The standard treatment guidelines for hospitals; TZH: Tercha zonal hospital; WHO: World health organization; WSUTRH: Wolaita Sodo University Teaching and referral hospital

\section{Acknowledgements}

We thank Wolaita Sodo University for providing seed money for this research. Pharmacists, Pharmacy technicians and nurses in the four hospitals in this study have assisted us in data collection. Therefore we would like to extend our heart-felt gratitude and appreciation to them. Finally, we are grateful for the kind assistance of Dr. Paula Kitto, a family physician, in language revision of this manuscript.

\section{Funding}

Wolaita Sodo University generously funded this research. There was no any influence of the University in the design of the study and collection, analysis, and interpretation of data and in writing the manuscript except monitoring project accomplishment and asking for a report.

\section{Availability of data and materials}

All necessary information is included in the body of this manuscript.

\section{Authors' contributions}

KD led design and execution of this study. TS, ZZ, and EW provided direct input on design, data management and data analysis. All authors participated in writing and editing the manuscript. All authors read and approved the final manuscript.

\section{Competing interest}

The authors declare that they have no competing interests.

\section{Consent for publication}

Not applicable.

\section{Ethics approval and consent to participate}

This research project was ethically approved and cleared by the institutional ethical review committee of the college of health sciences and medicine at Wolaita Sodo University. Eventually, the medical directors in the four hospitals were communicated about the ethical clearance of the study protocol and it was formally permitted to be conducted in the respective hospitals. A verbal consent from each patient to participate in the study was obtained before the interview.

\section{Author details}

'School of public health, College of health Sciences and Medicine, Wolaita Sodo University, Wolaita Sodo, Ethiopia. ${ }^{2}$ School of Medicine, College of health Sciences and Medicine, Wolaita Sodo University, Wolaita Sodo, Ethiopia.
Received: 16 August 2015 Accepted: 28 October 2016

Published online: 10 November 2016

\section{References}

1. Anthonia A. Assessing and Assuring Quality of Health Care in Africa. Afr J Med Sci. 2010;3(1):31-6.

2. Declaration of Alma-Ata International Conference on Primary Health Care, Alma-Ata, USSR, 6-12 September 1978. Available from http://www.who.int/ hpr/NPH/docs/declaration_almaata.pdf. Accessed 30 July 2015.

3. WHO. Introduction to Drug Utilization Research/ WHO International Working Group for Drug Statistics Methodology. Oslo, Norway: WHO Collaborating Centre for Drug Statistics Methodology, WHO Collaborating Centre for Drug Utilization Research and Clinical Pharmacological; 2003.

4. WHO. How to investigate drug use in health facilities, selected drug use indicators. Geneva: Action programme onEssential Drugs; 1993; p. 9-31.

5. WHO. WHO Medicines Strategy: Framework for action Essential drugs and Medicines policy 2000-2003. Geneva: WHO; 2000. WHO/EDM/2000.1.

6. WHO. The use of Essential Drugs. $6^{\text {th }}$ Report of the Expert Committee. Geneva: WHO Technical Report Series 850.3; 1995. Accessed at http://apps. who.int/iris/bitstream/10665/37340/1/WHO_TRS_850.pdf.

7. Hogerzeil HV, Walker GJA, Sallami AO, Fernando G. Impact of an essential drugs program on availability and rational use of drugs. Lancet. 1989; 1(8630):141-2

8. WHO. World Health Organization promoting rational use of medicines: core components. WHO Policy and Perspectives on medicine no.5. Document WHO/ EDM/2002.3. Geneva: WHO; 2002.

9. Debalto $D$, Gobe Z, Teklemariam S. A base line survey of prescribing indicators and factors influencing prescribing in southern Ethiopia. J Health Dev. 1991;11(3):263-7.

10. Summoro TS, Gidebo KD, Kanche ZZ, Woticha EW. Evaluation of trends of drug-prescribing patterns based on WHO prescribing indicators at outpatient departments of four hospitals in Southern Ethiopia. Drug Des Devel Ther. 2015;9:4551-5557.

11. Angamo MT, Wabe NT, Raju NJ. Assessment of Patterns of Drug use by using World Health Organization's Prescribing, Patient Care and Health facility indicators in Selected Health Facilities in Southwest Ethiopia. J Appl Pharm Sci. 2011;01(07):62-6.

12. Hogerzeil HV, Bimo, Ross-Degnan D, Laing RO, Ofori-Adjei D, Santoso B, Azad Chowdhury AK, Das AM, Kafle KK, Mabadeje AF. Field tests for rational drug use in twelve developing countries. Lancet. 1993;342(8884):1408-10.

13. Laing $\mathrm{RO}$, Hogerzeil HV. Ten recommendations to improve use of medicines in developing countries. Health Policy Plan. 2001;16(1):13-20. Oxford University Press.

14. Gopalakrishnan S, Ajitha K, Ganeshkumar P, Selvaraj I, Logaraj M. Assessment of patient care and health facility indicators among urban and rural private practitioners in Kancheepuram district of Tamil Nadu, India. NatJResComMed. 2012;1(4):178-241.

15. Deveugele M, Derese A, Brink-Muinen A, Bensing J, Maeseneer JD. Consultation length in general practice: cross sectional study in Six European countries. BMJ. 2002;325:472. 1.

16. Abdul Rasool BK, Fahmy SA, Abu-Gharbieh EF, Ali HS. Professional practices and perception towards rational use of medicines according to WHO methodology in United Arab Emirates. Pharmacy Practice. 2010;8:70-6.

17. El Mahalli AA, Akl OAM, Al-Dawood SF, Al-Nehab AA, Al-Kubaish HA, Al-Saeed SI, Elkahky AAA, Salem AMAA. WHO/INRUD patient care and facility-specific drug use indicators at primary health care centers in Eastern province, Saudi Arabia. East Mediterr Health J. 2012;18(11):1086-90.

18. WHO. Policy Perspective on Medicines; Promoting rational use of medicines; Core components, September 2002, Geneva.

19. Otoom S, et al. Evaluation of drug use in Jordan using World Health Organization prescribing indicators. East Mediterr Health J. 2002;8:000-0.

20. Ghimire $S$, Nepal S, Bhandari S, Nepal P, Palaian S. A prospective surveillance of drug prescribing and dispensing in a teaching hospital in Western Nepal. J Pak Med Assoc. 2009:59:726-31.

21. Sutharson L, Hariharan RS, Vamsadhara C. Drug utilization study in diabetology outpatient setting of a tertiary hospital. Indian J Pharmacol. 2003;35:237-40.

22. Massele AY, Nsimba SE, Rimoy G. Prescribing habits in church-owned primary health care facilities in Dar Es Salaam and other Tanzanian coast regions. East Afr Med J. 2001;78:510-4. 
23. Hazra A, Tripathi SK, Alam MS. Prescribing and dispensing activities at the health facilities of a non-governmental organization. Natl Med J India. 2000;13:177-82.

24. Karande S, Sankhe P, Kulkarni M. Patterns of prescription and drug dispensing. Indian J Pediatr. 2005;72:117-21.

25. Keohavong B, Syhakhang L, Sengaloundeth S, Nishimura A, Ito K. Rational use of drugs: prescribing and dispensing practices at public health facilities in Lao PDR. Pharmacoepidemiol Drug Saf. 2006;15:344-7.

26. Federal Democratic Republic of Ethiopia, Ministry of Health (FMOH). Assessment of the Pharmaceutical Sector in Ethiopia. 2003.

27. Good Dispensing Practice Manual. Drug Administration and Control Authority of Ethiopia. 2005. Addis Ababa.

Submit your next manuscript to BioMed Central and we will help you at every step:

- We accept pre-submission inquiries

- Our selector tool helps you to find the most relevant journal

- We provide round the clock customer support

- Convenient online submission

- Thorough peer review

- Inclusion in PubMed and all major indexing services

- Maximum visibility for your research

Submit your manuscript at www.biomedcentral.com/submit
Biomed Central 